Published in final edited form as:

Nat Immunol. 2005 November ; 6(11): 1133-1141.

\title{
A distinct lineage of CD4 T cells regulates tissue inflammation by producing interleukin 17
}

\author{
Heon Park ${ }^{1,5}$, Zhaoxia Li ${ }^{1,5}$, Xuexian O Yang 2,5 , Seon Hee Chang $^{2}$, Roza Nurieva ${ }^{2}$, Yi-Hong \\ Wang $^{2}$, Ying Wang ${ }^{1}$, Leroy Hood ${ }^{3}$, Zhou Zhu ${ }^{4}$, Qiang Tian ${ }^{3}$, and Chen Dong ${ }^{2}$ \\ 1 Department of Immunology, University of Washington, Seattle, Washington 98195, USA. \\ 2 Department of Immunology, MD Anderson Cancer Center, Houston, Texas 77030, USA. \\ 3 Institute for Systems Biology, Seattle, Washington 98103, USA. \\ 4 Johns Hopkins University School of Medicine, Baltimore, Maryland 21224, USA.
}

\begin{abstract}
Interleukin 17 (IL-17) has been linked to autoimmune diseases, although its regulation and function have remained unclear. Here we have evaluated in vitro and in vivo the requirements for the differentiation of naive CD4 T cells into effector T helper cells that produce IL-17. This process required the costimulatory molecules CD28 and ICOS but was independent of the cytokines and transcription factors required for T helper type 1 or type 2 differentiation. Furthermore, both IL-4 and interferon- $\gamma$ negatively regulated Thelper cell production of IL-17 in the effector phase. In vivo, antibody to IL-17 inhibited chemokine expression in the brain during experimental autoimmune encephalomyelitis, whereas overexpression of IL-17 in lung epithelium caused chemokine production and leukocyte infiltration. Thus, IL-17 expression characterizes a unique T helper lineage that regulates tissue inflammation.
\end{abstract}

CD4 T helper $\left(\mathrm{T}_{\mathrm{H}}\right)$ lymphocytes are essential regulators of immune responses and inflammatory diseases. After being activated by professional antigen-presenting cells (APCs), $\mathrm{T}_{\mathrm{H}}$ cells differentiate into effector cells specialized in cytokine secretion and function. Effector $\mathrm{T}_{\mathrm{H}}$ cells have been classified as type $1\left(\mathrm{~T}_{\mathrm{H}} 1\right)$ and type $2\left(\mathrm{~T}_{\mathrm{H}} 2\right)$ based on their cytokine expression profiles and immune regulatory function ${ }^{1} . \mathrm{T}_{\mathrm{H}} 1$ cells produce interferon- $\gamma$ (IFN- $\gamma$ ) and mediate cellular immunity, whereas $\mathrm{T}_{\mathrm{H}} 2$ cells produce interleukin 4 (IL-4), IL-5 and IL-13 and mediate humoral immunity and allergic responses. $\mathrm{T}_{\mathrm{H}}$ cell differentiation is regulated by the interaction of naive CD4 T cells with innate immune cells that express specific peptidemajor histocompatibility complex class II complexes, costimulatory molecules and inflammatory cytokines.

Naive $\mathrm{T}$ cell activation normally requires two signals: $\mathrm{T}$ cell receptor (TCR) signals, and costimulation through several accessory molecules. The main costimulatory molecule on $\mathrm{T}_{\mathrm{H}}$ cells is CD28 (ref. 2), which interacts with CD80 (B7-1) and CD86 (B7-2) expressed on mature dendritic cells and other APCs. The inducible costimulator ICOS is another member of the CD28 'superfamily' that also regulates naive CD4 T cell activation and effector differentiation ${ }^{3}$. In addition to TCR and costimulatory molecules, IL- 12 produced by activated APCs is critical in $\mathrm{T}_{\mathrm{H}} 1$ differentiation ${ }^{4}$. Additional cytokines in the IL-12 family, IL-23 and

\footnotetext{
Correspondence should be addressed to C.D. (cdong@ mdanderson.org)..

5 These authors contributed equally to this work.

COMPETING INTERESTS STATEMENT

The authors declare that they have no competing financial interests.

Reprints and permissions information is available online at http://npg.nature.com/reprintsandpermissions/
} 
IL-27, are also important for $\mathrm{T}_{\mathrm{H}}$ cell differentiation and function ${ }^{5,6}$. IL-23, in particular, is crucial in the pathogenesis of experimental autoimmune encephalomyelitis (EAE) and collagen-induced arthritis 7,8 . Other cytokines also influence the development of effector functions of $\mathrm{T}_{\mathrm{H}}$ cells; for example, IL-4 produced by activated $\mathrm{T}$ cells (and perhaps by other innate cells as well) is crucial in driving $\mathrm{T}_{\mathrm{H}} 2$ differentiation ${ }^{9}$.

$\mathrm{T}_{\mathrm{H}}$ differentiation and effector cytokine expression are mediated by several key transcription factors. IL-12 regulates $T_{H} 1$ differentiation through activation of the transcription factor STAT4 (refs. $4,{ }^{5}$ ). The transcription factor T-bet is a 'master regulator' of $\mathrm{T}_{\mathrm{H}} 1$ differentiation through the potentiation of IFN- $\gamma$ production and suppression of $\mathrm{T}_{\mathrm{H}} 2$-associated cytokine expression ${ }^{4}$. IL-4, in contrast, drives $\mathrm{T}_{\mathrm{H}} 2$ differentiation through the actions of STAT6 (ref. 9) and GATA-3, which is a 'master regulator' of $\mathrm{T}_{\mathrm{H}} 2$ differentiation through potentiation of IL-4 and suppression of IFN- $\gamma^{10}$. In addition, c-Maf has been identified as a $\mathrm{T}_{\mathrm{H}} 2$-specific transcription factor that binds to the $I l 4$ proximal promoter ${ }^{11}$. Studies of Maf-knockout mice and mice with overexpression of a Maf transgene, furthermore, have indicated that c-Maf selectively regulates $I l 4$ expression 11,12 .

IL-17 (also called IL-17A) has been associated with many inflammatory diseases such as rheumatoid arthritis, asthma, lupus and allograft rejection ${ }^{13-15}$. The IL-17 receptor (IL-17R) is distributed ubiquitously in various tissues ${ }^{14}$, and its engagement activates both transcription factor NF- $\mathrm{KB}$ and kinase Jnk pathways ${ }^{16}$. Many in vitro studies have indicated a proinflammatory function for IL-17 (ref. 15). In particular, IL-17 has been linked to tissue neutrophil recruitment through the induction of granulocyte colony-stimulating factor and IL-8 (ref. 15), and IL-17R-deficient mice have impaired host defense against microbacterial infection because of a substantial reduction in granulocyte colony-stimulating factor and macrophage inflammatory protein 2 in the lung ${ }^{17}$. IL-17 is also important in contact, delayedtype and airway hypersensitivities, as shown in a study using IL-17-deficient mice ${ }^{18}$. In related reports, IL-17-deficient mice ${ }^{19}$, as well as wild-type mice that received an IL-17R antagonist ${ }^{20}$, have shown resistance to an arthritis-like disease.

IL-17 expression is generally thought to be restricted to T cells. In humans, IL-17 is expressed by activated CD 4 cells and by $\mathrm{T}_{\mathrm{H}} 1$ and $\mathrm{T}_{\mathrm{H}} 0$ cells but not by $\mathrm{T}_{\mathrm{H}} 2$ cells 21 , whereas in mice, IL-17 expression is strongly induced by IL-23 in memory T cells ${ }^{22}$. Notably, IL-23 (but not IL-12) deficiency is associated with resistance to EAE and collagen-induced arthritis 7,8 , a phenotype that correlates with a defect in IL-17 expression 8,23 . IL-23 also selectively expands IL-17-expressing T cell populations, which may also coexpress another IL-17 family cytokine, IL-17F, as well as tumor necrosis factor (TNF) and IL-6 (ref. 23). These data suggest that a unique cytokine requirement is needed for generating T cells that express IL-17.

Here we have analyzed the regulation and function of IL-17 in vitro and in vivo. We found that IL-17 was expressed by a distinct lineage of $\mathrm{T}_{\mathrm{H}}$ effector cells; generation of these cells required CD28 and ICOS costimulation and was independent of the cytokine and transcription programs normally associated with $\mathrm{T}_{\mathrm{H}} 1$ and $\mathrm{T}_{\mathrm{H}} 2$ differentiation. In vivo, IL-17 potently regulated chemokine expression by tissue cells, and IL-17 overexpression in the lung caused airway inflammation. In contrast, IL-17-specific inhibition attenuated immune infiltration in the brain in an EAE model. We conclude from these data that IL-17 is expressed by a previously unknown subset of $\mathrm{T}_{\mathrm{H}}$ cells and is crucial in regulating tissue inflammatory reactions.

\section{RESULTS}

\section{Generation of IL-17-expressing $T_{H}$ cells requires CD28 and ICOS}

We hypothesized that antigen-specific naive $\mathrm{T}_{\mathrm{H}}$ precursor cells differentiate into IL-17expressing effector cells during immune responses. To test this, we immunized C57BL/6 (B6) 
mice with myelin oligodendrocyte glycoprotein (MOG) peptide and, after $7 \mathrm{~d}$, isolated spleen and lymph node cells and restimulated them with MOG peptide in vitro for cytokine production. We detected IL-17, IFN- $\gamma$ and TNF in supernatants only after restimulation (Fig. 1a). In contrast, nonimmunized mice or those receiving only complete Freund's adjuvant (CFA) produced neither IL-17 nor IFN- $\gamma$. We obtained similar results by intracellular cytokine staining of MOG-restimulated spleen and lymph node cells. The numbers of IL-17-producing CD4 cells were substantially and reproducibly increased after MOG immunization and did not express IFN- $\gamma$ (Fig. 1b). These results indicated that naive MOG-specific $\mathrm{T}_{\mathrm{H}}$ cells differentiated into IL-17-producing effector cells in vivo after immunization with MOG peptide.

IFN- $\gamma$ and TNF are also expressed by effector CD8 T cells ${ }^{24}$. To determine if CD8 T cells could also be stimulated to produce IL-17, we immunized B6 mice with keyhole limpet hemocyanin (KLH) protein, which elicits both CD4 and CD8 responses. We isolated spleen cells and, as with the CD4 T cells, stained them to assess intracellular expression of cytokines. In contrast to antigen-specific CD4 T cells, the KLH-specific CD8 T cells expressed IFN- $\gamma$ but much less IL-17 (Fig. 1c).

To further characterize the requirements for IL-17 expression, we next analyzed the function of CD28 and ICOS in the generation of IL-17-producing CD4 effector cells. First, we isolated ovalbumin (OVA)-specific TCR-transgenic CD4 T cells (OTII cells) from wild-type or ICOSdeficient mice and cultured them for $4 \mathrm{~d}$ with OVA peptide-loaded spleen cells from wild-type B6 mice or B7-deficient mice $\left(C d 80^{-1-} C d 86^{-1-}\right)$. Only OTII T cells positive for the variable $\alpha 2$-chain $\left(\mathrm{V}_{\alpha} 2^{+}\right)$remained in culture and had upregulated the activation marker CD44 and downregulated the cell surface marker CD62L (data not shown). We then washed the activated OTII cells and restimulated them for $24 \mathrm{~h}$ with antibody to CD3 (anti-CD3), after which we assessed cytokine production in cell supernatants by ELISA. Supernatants from cells deficient in CD28 costimulation (wild-type CD4 T cells plus B7-deficient APCs) contained much less IL-4, IFN- $\gamma$ and IL-17 than did wild-type CD4 T cells and wild-type APCs (Fig. 1d). In contrast, $\mathrm{T}$ cells deficient in ICOS costimulation (ICOS-deficient CD4 T cells and wild-type APCs) produced both less IL-4 and IL-17 and more IFN- $\gamma$ than did wild-type CD4 T cells and wildtype APCs (Fig. 1d). Finally, deficiencies in both B7 and ICOS caused the most profound cytokine defect, as T cells did not produce IFN- $\gamma$, IL-4, or IL-17 after restimulation (Fig. 1d). Consistent with that, naive ICOS-deficient $\left(\operatorname{Icos}^{-1-}\right) \mathrm{CD} 4 \mathrm{~T}$ cells, when activated with antiCD3 and wild-type APCs, demonstrated defects in the production of IL-4 and IL-17 (Fig. 1e). ICOS is thus differentially required for the development of $\mathrm{T}_{\mathrm{H}}$ cells into different effector subsets.

To understand the function of CD28 and ICOS in IL-17 regulation in vivo, we used wild-type B6 mice and mice deficient in B7, ICOS or both and immunized the mice with KLH in CFA. Consistent with the in vitro results, during ex vivo recall responses, T cells from mice deficient in B7 produced much less IFN- $\gamma$, IL-17 and IL-4, whereas ICOS deficiency resulted in the production of less IL-4 and IL-17 but not IFN- $\gamma$ (Fig. 1f). T cells from mice deficient in expression of both B7 and ICOS produced none of the cytokines found after stimulation of cells from mice with single deficiencies in response to KLH restimulation. Thus, both the in vitro and in vivo data indicated that CD28 and ICOS had specific and overlapping functions in the development of antigen-specific $\mathrm{T}_{\mathrm{H}}$ subsets from naive $\mathrm{T}$ cells and that the generation of IL-17-expressing $\mathrm{T}_{\mathrm{H}}$ cells was regulated by both CD28 and ICOS. Additionally, in the absence of both CD28 and ICOS costimulation, T cells did not differentiate into effector cells capable of expressing IFN- $\gamma$, IL-4 or IL-17.

\section{Regulation of IL-17 effector cell differentiation}

Many studies have demonstrated that cytokine environment is critical for the development of polarized $\mathrm{T}_{\mathrm{H}}$ effector subsets with unique functions ${ }^{1}$. To determine which cytokines were 
required for the development of IL-17-expressing T cells, we incubated OTII cells for $5 \mathrm{~d}$ with OVA peptide-loaded B6 splenocytes in the absence or presence of anti-IL-4, anti-IFN- $\gamma$ or IL-23, restimulated the cells with anti-CD3 and then evaluated cytokine expression by ELISA (Fig. 2a). IL-17 expression was increased substantially when anti-IFN- $\gamma$ was added during $\mathrm{T}_{\mathrm{H}}$ differentiation, suggesting that IFN- $\gamma$ negatively regulates the generation of IL-17producing cells. IL-4 production and $\mathrm{T}_{\mathrm{H}} 2$ differentiation were also increased in the presence of anti-IFN- $\gamma$. Additionally, anti-IL-4 inhibited $\mathrm{T}_{\mathrm{H}} 2$ differentiation and, when added in combination with anti-IFN- $\gamma$, further increased IL-17 expression. Finally, the addition of IL-23 together with anti-IL-4 and anti-IFN- $\gamma$ led to the most IL-17 production, which we confirmed by intracellular cytokine staining. In contrast, there were very few IL-17-expressing $\mathrm{V}_{\alpha} 2^{+} \mathrm{OTII}$ cells after activation in neutral conditions (Fig. 2a). Finally, the combination of anti-IFN- $\gamma$, anti-IL-4 and IL-23 greatly facilitated the differentiation of $\mathrm{T}_{\mathrm{H}}$ cells into IL-17-expressing cells, resulting in expression of IL-17 by more than $20 \%$ of the OTII T cells (Fig. 2a). These in vitro experiments indicated that the differentiation of IL-17-producing cells occurred efficiently only in the absence of $\mathrm{T}_{\mathrm{H}} 1$ and $\mathrm{T}_{\mathrm{H}} 2$ cell development.

We further analyzed the development of IL-17-expressing cells in vivo. We immunized mice deficient in IFN- $\gamma$ with MOG peptide in CFA and assessed cytokine expression by intracellular cytokine staining and ELISA after MOG restimulation of T cells ex vivo. In cells from IFN- $\gamma-$ deficient mice, both the number of IL-17-expressing cells and the amount of IL-17 secretion after MOG restimulation were moderately but consistently increased (Fig. 2b), supporting the conclusion that $\mathrm{T}_{\mathrm{H}}$ cell effector differentiation to IL-17-producing $\mathrm{T}_{\mathrm{H}}$ cells in vivo is negatively regulated by IFN- $\gamma$. Using the same immunization protocol, we found that IL-4 was not detectable after restimulation and there was no difference in IL-17 expression in IFN- $\gamma$ knockout mice after treatment with either anti-IL-4 or a control antibody (data not shown).

Because $T_{H} 1$ and $T_{H} 2$ differentiation are regulated by complex transcriptional mechanisms, we next evaluated STAT4-deficient and STAT6-deficient mice and BALB/c control mice that we immunized with KLH in CFA. As before, we restimulated cells from the spleen and lymph node ex vivo with KLH. Unlike IL-4 and IFN- $\gamma$, whose production is greatly reduced in T cells from STAT6-deficient and STAT4-deficient mice, respectively, there was no difference in IL-17 production compared with that of control mice (Fig. 2c). To analyze the involvement of T-bet in IL-17 expression, we immunized B6 or T-bet-deficient mice with MOG and measured IL-17 and IFN- $\gamma$ expression ex vivo. Although both the number of IFN- $\gamma$-expressing cells and the production of IFN- $\gamma$ were much lower in the absence of T-bet, the number of IL-17 cells and the production of IL-17 much higher in T-bet-deficient mice after immunization (Fig. 2d). To assess the involvement of c-Maf, the $\mathrm{T}_{\mathrm{H}} 2$ transcription factor important for IL-4 expression, in IL-17 expression, we purified naive $\mathrm{CD} 4^{+} \mathrm{T}$ cells from mice with or without a c-Maf transgene on an $\mathrm{Iocs}^{+/-}$or $\mathrm{ICOS}^{-/}$background and activated them for $4 \mathrm{~d}$ with anti-CD3 and wild-type APCs. After restimulation, cells overexpressing c-Maf produced much more IL-4, but their expression of IL-17 as well as IFN- $\gamma$ was much less (Fig. 1e). Thus, c-Maf seems to negatively regulate IL-17 and IFN- $\gamma$ expression. In summary, our in vitro and in vivo experiments indicated that the cytokine and transcription programs regulating the differentiation of $\mathrm{T}_{\mathrm{H}}$ cells into IL-17-expressing cells were distinct from those known to be critical for $\mathrm{T}_{\mathrm{H}} 1$ and $\mathrm{T}_{\mathrm{H}} 2$ cells.

\section{Regulation of IL-17 expression in effector or memory T cells}

IFN- $\gamma$ expression by $\mathrm{T}_{\mathrm{H}} 1$ cells can be activated by concomitant stimulation with cytokines (IL-12 plus IL-18) and TCR stimulation ${ }^{25}$. To study mechanisms that may regulate IL-17 expression in the effector phase, we sorted $\mathrm{CD} 4{ }^{+} \mathrm{CD} 62 \mathrm{~L}^{10} \mathrm{CD} 4 \mathrm{~T}$ cells, treated them with various stimuli and then measured IL-17 production. After TCR and CD28 stimulation for 36 h, we detected IL-17 production in culture supernatants (Fig. 3a). We also evaluated the effect 
of IFN- $\gamma$ and IL-4 on IL-17 production. The addition of exogenous IFN- $\gamma$ or IL-4 alone did not affect the amount of IL-17 produced, whereas in combination they caused a moderate reduction in IL-17 (Fig. 3a). As effector or memory T cells in these conditions might produce large amounts of these two cytokines as well, we tested the effect of blocking with neutralizing antibodies. Treatment with anti-IL-4, anti-IFN- $\gamma$ or both greatly increased IL-17 production (Fig. 3a). We also found that B1S1 (ref. 26), a negative regulator of T cell activation, inhibited TCR-driven IL-17 expression (data not shown). In addition, because IL-23 induces IL-17 expression by effector and memory $\mathrm{T}$ cells ${ }^{22}$, we evaluated the effects of adding IFN- $\gamma$ or IL-4 on IL-17 expression induced by IL-23. IFN- $\gamma$ had no effect, whereas IL-4 strongly inhibited IL-23-dependent IL-17 expression (Fig. 3b).

\section{IL-17 regulates chemokine expression}

Although it is known that the $\mathrm{T}_{\mathrm{H}} 1$ cytokine IFN- $\gamma$ regulates cell-mediated immunity and $\mathrm{T}_{\mathrm{H}} 2$ cytokines (IL-4 and IL-13) regulate humoral responses, the function of IL-17 is not understood as well. Published data have indicated that IL-17 is a proinflammatory mediator on multiple cell types in vitro ${ }^{14}$ and acts in synergy with TNF to regulate inflammatory gene expression $^{27}$. To better understand the direct action of IL-17 in immune responses, we did gene expression profiling analysis with an IL-17 recombinant protein that contains a human immunoglobulin G1 (IgG1) tag (IL-17-Ig) ${ }^{28}$. Treatment of mouse embryonic fibroblasts (MEFs) with IL-17-Ig induced IL-6 production that was inhibited by anti-IL-17 (Supplementary Fig. 1 online). Next, we treated MEFs for $6 \mathrm{~h}$ with human IgG or IL-17-Ig and then prepared total RNA for DNA microarray analysis. We used a combined data processing strategy that takes into account both 'fold changes' and the $\lambda$-value (which is a monotonically increasing function of likelihood ratio describing how likely the gene is differentially expressed for each spot on the array; we arbitrarily chose 'fold changes' of more than 1.5 or $\lambda$-values greater than 19.5 as cutoffs). Approximately 60 genes were upregulated by IL-17, many encoding proinflammatory molecules, including chemokines and matrix metalloproteinases (Table 1). We found upregulation of expression of genes encoding chemokines CCL2, CCL7, CXCL1 and CCL20, as well as matrix metalloproteinases 3 and 13, and subsequently confirmed that finding by RT-PCR (Fig. 4). Thus, IL-17 seems to directly induce inflammatory responses in primary fibroblasts.

IL-17 has been suggested as being important for EAE pathogenesis ${ }^{23}$. To examine the mechanisms whereby IL-17 regulates central nervous system (CNS) inflammation, we used anti-IL-17, which inhibited IL-6 induction in MEFs treated with IL-17 but not in those treated with IL-17F (Supplementary Fig. 1 online). As T cells reportedly infiltrate the CNS by day 7 after MOG immunization ${ }^{23}$, we immunized B6 mice twice with MOG peptide and treated them intraperitoneally with anti-IL-17 or control rat IgG starting on day 9 and continuing every other day for a total of three injections. This treatment regimen resulted in a considerably delayed onset of disease compared with that of control mice (day 18 versus day 12; Fig. 5a). At $6 \mathrm{~d}$ after the last antibody administration, the mice treated with anti-IL-17 began to develop signs of EAE. Consistent with the clinical signs, there was a characteristic mononuclear cell infiltrate in the white matter of spinal cords of mice treated with rat $\mathrm{IgG}$, whereas there was no obvious cellular infiltration in mice treated with anti-IL-17 (data not shown). To further test the effect of anti-IL-17 after the onset of EAE, we delayed the antibody treatment until the mice used in the experiment developed signs of EAE. Even at this late stage, anti-IL-17 reversed the progression of EAE and resulted in reduced numbers of CD4 T cells and CD11 $\mathrm{b}^{+}$ macrophages in the CNS (Supplementary Fig. 2 online).

To determine if treatment with anti-IL-17 attenuated the activation of MOG-specific T cells in EAE, we obtained splenocytes from control mice and mice treated with anti-IL-17 and restimulated the cells ex vivo with MOG peptide. T cell proliferation and expression of 
proinflammatory cytokines TNF, IFN- $\gamma$ and IL- 17 were not inhibited by treatment with antiIL-17 (Fig. 5b and Supplementary Fig. 2 online). Thus, these data demonstrated that blocking IL-17 in the effector phase of EAE does not result in reduced generation or tolerance of autoreactive $\mathrm{T}$ cells.

We then determined the basis for lack of recruitment of autoreactive $\mathrm{T}$ cells and macrophages into the CNS in the mice treated with anti-IL-17. During EAE, several chemokines are induced considerably in the $\mathrm{CNS}^{29}$. Monocyte chemotactic peptide 1 and its receptor CCR2 have been suggested to be prominent during EAE initiation ${ }^{30}$. We therefore used real-time RT-PCR to assess chemokine expression in brain tissue after neutralization of IL-17. The expression of chemokines CCL2, CCL17 and CXCL1 was inhibited considerably after IL-17 blockade (Fig. $5 c)$. These data suggest that IL-17 derived from infiltrating $\mathrm{T}_{\mathrm{H}}$ cells probably mediates the inflammatory reactions in the CNS through regulation of chemokine induction.

\section{II17 transgene overexpression causes inflammation in lungs}

To further understand the action of IL-17 in vivo, we generated transgenic mice that expressed $1 l 17$ in lung epithelial cells using the $C c 10$ promoter (Fig. 6a). We obtained two independent transgenic lines in which IL-17 production in bronchoalveolar lavage fluid could be detected by ELISA (Fig. 6b) and IL-17 mRNA could be detected by RT-PCR in total lung RNA (Fig. $6 c)$. The independent lines had similar phenotypes in lung pathology; however, male transgenic mice of one line developed disease much more slowly than their female littermates.

We did histological analysis to determine the consequences of chronic overexpression of IL-17. At 3 months of age, Ill7-transgenic mice had hypertrophic lung epithelium in the bronchus and bronchiole and obvious alveolar wall thickening compared with that of littermate control mice (data not shown). After 3 months of age, large, eosinophilic and sometimes multinucleated macrophages were frequently present in the lung parenchyma of the Ill7-transgenic mice; between 5 and 10 months of age, Ill7-transgenic mice had focal accumulation and infiltration of mononuclear cells, including nodular collections of mononuclear CD4 lymphocytes (Fig. 6d,e and data not shown). Long, thin, needle-like crystals in the bronchioles (Fig. 6f) and mucus production by epithelial cells, visualized by periodic acid Schiff staining, were present in Il17-transgenic but not control mice (Fig. 6d). Masson's trichrome staining also indicated substantial amounts of collagen on the subepithelium of bronchioles adjacent to lymphocyte aggregates in Il17-transgenic mice (Fig. 6d). In contrast, control littermates had only loosely packed collagen.

We compared cytokine and chemokine gene expression profiles in lung tissues of Ill7transgenic mice and their littermate controls. We did not find upregulation of several $\mathrm{T}_{\mathrm{H}} 2$ associated genes (Il4, Il5, Il9 and Ill3; data not shown). However, the expression of several chemokines (CCL7, CCL22, CCL20, CCL11 and CX3CL1) was greatly increased (Fig. 6c). We also found increases in the matrix metalloproteinase inhibitor TIMP-1 and matrix metalloproteinase 9 , which has been noted in patients with airway inflammation 31,32 . To determine if the induction of these inflammatory genes was directly caused by signals produced by IL-17, we treated MLE12 cells (a mouse lung epithelial cell line) with IL-17-Ig and then measured expression of those same genes. We noted a very similar expression profile of the genes discussed above in MLE12 cells after $6 \mathrm{~h}$ of treatment with IL-17-Ig, as well as treatment with TNF and IL-1 $\beta$ (Fig. 6g). Other chemokines such as CCL1, CCL2 and CXCL1 were also upregulated by IL-17. These data indicate that IL-17 acts directly on epithelial cells to induce chemokine expression and that chronic IL-17 overproduction results in leukocyte infiltration and airway changes. 


\section{DISCUSSION}

Activation of CD4 T lymphocytes by APCs in the presence of specific cytokines causes differentiation into distinct effector $\mathrm{T}_{\mathrm{H}}$ subsets (or lineages) that produce cytokines with immune regulatory functions. Here we have characterized the regulation of IL-17 expression by $\mathrm{CD} 4 \mathrm{~T}$ cells and the function of IL-17 in producing inflammatory reactions in vivo. IL-17 was produced by a unique subset of $\mathrm{T}_{\mathrm{H}}$ cells during immune and autoimmune responses and IL-17 had a critical function in vivo in regulating chemokine expression and tissue inflammation. Thus, these IL-17-producing effector T cells are important in inflammatory responses (Supplementary Fig. 3 online).

Although IL-17 has emerged as a crucial regulator in immune responses and diseases, its regulation is still poorly understood. Consistent with published reports $8,23,33$, we found that IL-17 was produced mainly by a subset of antigen-specific effector CD4 T cells in immune and autoimmune responses. Furthermore, differentiation of naive CD4 T cells to IL-17producing effector T cells was mediated by the innate immune system through CD28 and ICOS costimulation. Although deficiency of B7-1 and B7-2 led to a reduction in all cytokines, ICOS stimulation seemed to be required for production of IL- 4 and IL-17 but not of IFN- $\gamma$. Compound deficiency in both CD28 and ICOS signals resulted in decreases in all $\mathrm{T}_{\mathrm{H}}$ subsets both in vitro and in vivo, supporting the idea that costimulation is required for proper activation of all $\mathrm{T}$ cell subsets for entry into effector differentiation programs.

Based on our analysis, differentiation of IL-17-producing effector T cells is independent of the mechanisms required for $\mathrm{T}_{\mathrm{H}} 1$ or $\mathrm{T}_{\mathrm{H}} 2$ cell development. IL-17 expression by CD4 $\mathrm{T}$ cells does not require IFN- $\gamma$ or the transcription factors T-bet or STAT4, all of which are essential regulators of $\mathrm{T}_{\mathrm{H}} 1$ differentiation. In contrast, our data have shown that IL-4 negatively regulates the development of IL-17-producing effector T cells and IL-17 expression. We also found that overexpression of c-Maf, a $\mathrm{T}_{\mathrm{H}}$ 2-acting transcription factor, greatly inhibited IL-17 as well as IFN- $\gamma$ expression. Thus, our data indicate that IL-17-producing effector T cells are a previously unknown subset of $\mathrm{CD} 4 \mathrm{~T}_{\mathrm{H}}$ cells.

The biological function of IL-17 also supports the conclusion that IL-17-producing effector T cells are a distinct $\mathrm{T}_{\mathrm{H}}$ subset. IFN- $\gamma$ produced by $\mathrm{T}_{\mathrm{H}} 1$ cells is well known for its importance in antigen presentation and cellular responses to intracellular bacteria and viruses. Likewise, IL-4 and other cytokines derived from $\mathrm{T}_{\mathrm{H}} 2$ cells have crucial functions in humoral immunity and allergic reactions. IL-17, in contrast, is important in tissue inflammation. We analyzed cellular responses to IL-17 and found that IL-17 induced expression of chemokines and matrix metalloproteinases in fibroblasts and lung epithelial cells, similar to the actions of TNF and IL-1. Those data are consistent with many reports in the literature supporting the idea of a proinflammatory function in vitro for IL-17 (ref. 15). We also found that blocking IL-17 resulted in attenuation and delay of EAE and reversed the progression of active EAE. Notably, the effect of anti-IL-17 could not be attributed to reduced T cell priming or cytokine expression but instead acted through the inhibition of chemokine upregulation in the CNS tissue.

Consistent with that, there were fewer CD4 T cells and macrophages in the CNS of mice treated with anti-IL-17. Those data indicate that IL-17 is important in chemokine expression and tissue inflammation in EAE.

We also developed two transgenic mouse lines that chronically overexpressed IL-17 in lung epithelial cells. We found substantial inflammation and other airway changes such as mucus production and subepithelial collagen deposition in the transgenic mice, but no apparent neutrophilia ${ }^{34,35}$. Instead, macrophages were the initial and dominant inflammatory cell type in the lung parenchyma starting as early as 3 months of age. Those findings, although different from the widely accepted idea regarding neutrophil recruitment as a chief function for IL-17, 
are in agreement with the hypothesis that IL-17 is critical in autoimmune diseases such as EAE and collagen-induced arthritis, in which macrophages are the main inflammatory cells. Furthermore, whereas mucus production and Charcot-Leyden-like crystals are associated with IL-13-transgenic mice ${ }^{36}$, we did not find evidence of $\mathrm{T}_{\mathrm{H}} 2$ cytokine expression in lungs of Ill7-transgenic mice. In contrast, several chemokines were increased in Ill7-transgenic mice, and they are probably the direct targets of IL-17, as treatment of a lung epithelial cell line with IL-17 resulted in upregulation of the genes encoding those chemokines. Thus, overexpression of IL-17 in lungs resulted in chemokine induction in epithelial cells and caused lung inflammation.

We have demonstrated here that IL-17 is crucial in inflammatory responses. Notably, the differentiation of IL-17-producing effector T cells and their IL-17 expression were negatively regulated by $\mathrm{T}_{\mathrm{H}} 1$ and $\mathrm{T}_{\mathrm{H}} 2$ cytokines. IL-12, IL-4 and IFN- $\gamma$ strongly inhibited the generation and population expansion of IL-17-expressing cells and their cytokine expression, which may serve as a protective strategy to 'fine-tune' the expression IL-17 so it does not cause excessive inflammation. Thus, balanced differentiation of $\mathrm{T}_{\mathrm{H}}$ cells is crucial for immunity and host protection. Abnormal expression of $\mathrm{T}_{\mathrm{H}} 1$ or $\mathrm{T}_{\mathrm{H}} 2$ cytokines will affect IL-17 expression and, in turn, may contribute to autoimmune disease.

In summary, we have characterized a previously unknown lineage of $\mathrm{T}_{\mathrm{H}}$ cells. These IL-17producing effector $\mathrm{T}$ cells produce IL-17 that regulates inflammatory chemokine expression and responses. Further research on this subset of $\mathrm{T}_{\mathrm{H}}$ cells should demonstrate greater complexity of $\mathrm{T}_{\mathrm{H}}$ cell regulation and function in immune responses. Additional research may also show that modulation of IL-17-producing effector T cells therapeutically is an important method for treating $\mathrm{T}$ cell-mediated chronic inflammatory diseases.

\section{METHODS}

\section{Generation of IL-17 recombinant protein}

The cDNA sequences encoding the mature form of mouse IL-17 were amplified by PCR and were sequenced before being subcloned into the DES-Ig vector consisting of an insect expression plasmid pMT/BiP/V5-His A (Invitrogen) backbone and a human IgG1 Fc tag 28 . The primers used for cDNA amplification, with $B g l \mathrm{II}$ and SpeI sites, respectively, were as follows: Ill7 forward, 5'-AGATCTGCGGCTACAGTGAAGGCA-3', and reverse, 5'ACTAGTGGCTGCCTGGCGGACAAT- $3^{\prime}$. According to the manufacture's protocol, the DES-IL-17-Ig construct was transfected together with a hygromycin-resistance plasmid (Invitrogen) into the drosophila cell line S2 to generate a stable cell line. After CuSO4 induction, IL-17-Ig fusion protein produced by the stable cell line was further purified with a protein A-agarose column (Sigma-Aldrich).

\section{Ex vivo T cell responses}

Mixed T cells and APCs from draining lymph nodes and spleen were prepared 7-11 d after immunization. Viable cells $\left(3.75 \times 10^{6}\right)$ were cultured in complete medium with or without MOG peptide (amino acids 35-55) at various concentrations. Supernatants from activated cells were collected $72 \mathrm{~h}$ later and TNF, IFN- $\gamma$ and IL-17 were measured by ELISA (BD Pharmingen). For intracellular cytokine staining, spleen and lymph node cells from immunized mice were stimulated for $24 \mathrm{~h}$ with peptide antigen, and GolgiPlug (BD Pharmingen) was added in the last $5 \mathrm{~h}$ or GolgiPlug plus $500 \mathrm{ng} / \mathrm{ml}$ of ionomycin and $50 \mathrm{ng} / \mathrm{ml}$ of phorbol 12-myristate 13-acetate (PMA; Sigma-Aldrich) were added for $5 \mathrm{~h}$. Cells were permeabilized with the Cytofix/Cytoperm Plus Kit (BD Pharmingen) according to the manufacturer's protocol. 


\section{$T_{H}$ differentiation}

Naive T cells, isolated from OTII mice by AutoMACS (Miltenyi Biotec) selection of CD4 T cells following the manufacturer's instruction, were cultured at a ratio of 1:1 with irradiated B6 splenic APC samples depleted of T cells, along with $10 \mu \mathrm{g} / \mathrm{ml}$ of OVA peptide (amino acids 323-339; ISQAVHAAHAEINEAGR) in the presence or absence of $100 \mathrm{ng} / \mathrm{ml}$ of IL-23 (R\&D systems), $10 \mu \mathrm{g} / \mathrm{ml}$ of anti-IL-4 (11B11) or $10 \mu \mathrm{g} / \mathrm{ml}$ of anti-IFN- $\gamma$ (XMG1.2) or 'cocktails' of these reagents. The medium was changed when necessary but the concentrations of IL-23, anti-IL-4 and/or anti-IFN- $\gamma$ were maintained. Then, $5 \mathrm{~d}$ after being activated, cells were restimulated with $500 \mathrm{ng} / \mathrm{ml}$ of ionomycin and $50 \mathrm{ng} / \mathrm{ml}$ of PMA, after which cells producing IL-17 and IFN- $\gamma$ were analyzed by intracellular staining as described above.

\section{DNA microarray protocol and data analysis}

Mouse arrays consisted of 16,463 oligonucleotide probes in the Mouse Genome Set Version 2.0 (QIAGEN/Operon). A Bio-Rad Versarray Chipwriter Pro with Telechem SMP3 spotting pins was used to spot these probes onto Corning GAPS2 substrates. Each oligonucleotide was spotted in duplicate on each array, such that the top and bottom halves of the array were identical. Probes were labeled by reverse transcription of total RNA with oligo(dT) primer (BD Bioscience) in the presence of indocarbocyanine- or indodicarbocyanine-labeled nucleotides to produce labeled cDNA. Labeled cDNA was then hybridized to arrays with Roche DIG hybridization buffer at $37^{\circ} \mathrm{C}$. A Packard BioChip ScanArray 5000 was used for scanning and MolecularWare's AnalyzerDG software was used for image analysis. Preprocessing of array data involved background subtraction followed by median normalization. Intensity measurements from three arrays, each containing two duplicates per probe, were combined for a total of six replicates per time point. A STATistical method that has been described ${ }^{37}$ was then used on these replicates to determine likelihood of differential expression for the transcript associated with each probe. A threshold on this differential expression score was then applied across all time points to yield a subset of genes that were differentially expressed in at least one time point, and the resulting data were analyzed further by cluster analysis with the JExpress computer program.

\section{RT-PCR}

Total RNA was extracted from homogenized brain tissue, lung tissue, MEFs or MLE12 cells (CRK-2100; American Type Culture Collection) with TRIzol reagent (Invitrogen) following the manufacturer's instructions. The cDNA was generated with an oligo(dT) primer (Invitrogen) and, for real-time PCR, was analyzed by Taqman PCR with the Brillian QPCR kit (Stratagene) based on expression of the reference gene (Actb, encoding $\beta$-actin). The following primer pairs were used: Actb, forward, $5^{\prime}$-TCCTTCGTTGCCGGTCC AC-3', and reverse, 5'-ACCAGCGCAGCGATATCGTC-3'; Mmp3 (matrix metalloproteinase 3), forward, 5'-TGCAGTTGGAGAACATGGAGACTT-3', and reverse, $5^{\prime}$ GTAGAGCTGCACATTGGTGATGTCT-3'; Mmp9, forward, 5'TGTACACAGGCAAGACCGTGCTG-3', and reverse, 5'-CTCATGGTCCAC CTTGTTCACCTC-3'; Mmp 13, forward, 5'-TTACCAGTCTCCGAGGAGAAA CTA-3', and reverse, 5'-GTCTTCCCCGTGTTCTCAAAGTGA-3'; Ccl2, forward, 5'CTCAGCCAGATGCAGTTAACGCCC-3', and reverse, $5^{\prime}$-GGTGCTG AAGACCTTAGGGCAGAT-3'; $C c l 7$, forward, 5'-CTCATAGCCGCTGCTTT CAGCATC-3', and reverse, 5'-GTCTAAGTATGCTATAGCCTCCTC-3'; Cxcll, forward, 5'CGCTTCTCTGTGCAGCGCTGCTGCT-3', and reverse, 5'-AAGC CTCGCGACCATTCTTGAGTG-3'; $\mathrm{Cxcl3}$, forward 5'-TGCAGGGCTTACGGC TAAGCCTCAG-3', and reverse 5'-GGCATGGATGGGTTCCTCTATCTT-3'; Ccl20, forward, 5'-ATGGCCTGCGGTGGCAAGCGTCTG-3', and reverse, 5'TAGGCTGAGGAGGTTCACAGCCCT-3'; Ccll1, forward, 5'-GCGCTTCTATT 
CCTGCTGCTCACGG-3', and reverse, 5'-GTGGCATCCTGGACCCACTTCT TC-3';

Icam 1 (intercellular adhesion molecule), forward, 5'-CAGGTCCAATTC

ACACTGAATGCC-3', and reverse, 5'-GTACACATTCCTGGTGACATTCCCA-3'; Timp1, forward, 5'-GCTTCCAGTAAGGCCTGTAGCTGT-3', and reverse,

GACCTGATCCGTCCACAAACAGTG-3'; Hprtl (hypoxanthine guanine phosphoribosyl

transferase), forward, 5'-GCTGGTGAAAAGGACCTCTGC-3', and reverse, 5'-

CACAGGACTAGAACACCTGC-3'.

\section{Generation of /l17-transgenic mice}

For the generation of $I l 17$-transgenic mice, the $C c 10$ promoter sequence (a gift from J. Elias, Yale University School of Medicine, New Haven, Connecticut) was cloned into pBluescript II with both flanking HindIII sites. Full-length cDNA encoding mouse Ill7 was first cloned into retrovirus vector containing an internal ribosomal entry site-green fluorescent protein (IRES-GFP) cassette (provided by K. Murphy, Washington University, St. Louis, Missouri) with $B g l I I$ and $X h o I$. The entire IL-17-IRES-GFP construct was cut out with $B g l I I$ and $B a m H I$ restriction enzymes and was ligated into pBluescript II containing the $C c 10$ promoter. Human growth hormone intronic and polyadenylation sequences were then inserted into the CC10-IL-17-IRES-GFP-pBluescript II construct using the BamHI and NotI restriction enzyme sites. The Ill7 transgene construct was isolated by digestion with NotI and SapI and was microinjected into B6 mice at the Transgenic Mouse Facility at University of Washington (Seattle, Washington). Two Il17-transgenic founders were obtained and were bred with B6 mice.

\section{EAE induction in mice}

Female B6 mice were purchased from Charles River and Jackson laboratory. For the induction of EAE, mice were immunized with the MOG peptide (amino acids 35-55; MEVGWYRSPFS ROVHLYRNGK) emulsified in CFA as described 26,38 . Anti-IL-17 or control rat IgG (100 $\mu \mathrm{g} /$ mouse each time) was administered at various times after MOG immunization. Signs of EAE were assigned scores on a scale of $1-5$ as follows: 0 , none; 1 , limp tail or waddling gait with tail tonicity; 2, wobbly gait; 3 , hindlimb paralysis; 4 , hindlimb and forelimb paralysis; 5 , death. All animal experiments used protocols approved by the Institutional Animal Care and Use Committees of the University of Washington (St. Louis, Missouri) and MD Anderson Cancer Center (Houston, Texas).

\section{Acknowledgements}

We thank L. Glimcher and I.-C. Ho for Maf-transgenic mice; L. Glimcher and C. Wilson for T-bet-deficient mice; J. Elias for the $C c 10$ promoter construct; A. Farr for guidance in animal work; and the Dong lab for help and discussions. Supported by the National Institutes of Health (C.D.), Arthritis Foundation (S.H.C., R.N. and C.D.), Cancer Research Institute (C.D.) and MD Anderson Cancer Center (C.D.).

\section{References}

1. Mosmann TR, Coffman RL. TH1 and TH2 cells: different patterns of lymphokine secretion lead to different functional properties. Annu Rev Immunol 1989;7:145-173. [PubMed: 2523712]

2. Lenschow DJ, Walunas TL, Bluestone JA. CD28/B7 system of T cell costimulation. Annu Rev Immunol 1996;14:233-258. [PubMed: 8717514]

3. Dong C, Nurieva RI. Regulation of immune and autoimmune responses by ICOS. J Autoimmun 2003;21:255-260. [PubMed: 14599850]

4. Szabo SJ, Sullivan BM, Peng SL, Glimcher LH. Molecular mechanisms regulating Th1 immune responses. Annu Rev Immunol 2003;21:713-758. [PubMed: 12500979]

5. Trinchieri G, Pflanz S, Kastelein RA. The IL-12 family of heterodimeric cytokines: new players in the regulation of T cell responses. Immunity 2003;19:641-644. [PubMed: 14614851] 
6. Robinson DS, O'Garra A, Steinman L, Gijbels K. Further checkpoints in Th1 development: CD4 ${ }^{+}$Tcell subsets in autoimmunity. Immunity 2002;16:755-758. [PubMed: 12121657]

7. Cua DJ, et al. Interleukin-23 rather than interleukin-12 is the critical cytokine for autoimmune inflammation of the brain. Nature 2003;421:744-748. [PubMed: 12610626]

8. Murphy CA, et al. Divergent pro- and antiinflammatory roles for IL-23 and IL-12 in joint autoimmune inflammation. J Exp Med 2003;198:1951-1957. [PubMed: 14662908]

9. Glimcher LH, Murphy KM. Lineage commitment in the immune system: the T helper lymphocyte grows up. Genes Dev 2000;14:1693-1711. [PubMed: 10898785]

10. Zheng W, Flavell RA. The transcription factor GATA-3 is necessary and sufficient for Th2 cytokine gene expression in CD4 T cells. Cell 1997;89:587-596. [PubMed: 9160750]

11. Ho IC, Hodge MR, Rooney JW, Glimcher LH. The proto-oncogene c-maf is responsible for tissuespecific expression of interleukin-4. Cell 1996;85:973-983. [PubMed: 8674125]

12. Kim JI, Ho IC, Grusby MJ, Glimcher LH. The transcription factor c-Maf controls the production of interleukin-4 but not other Th2 cytokines. Immunity 1999;10:745-751. [PubMed: 10403649]

13. Aggarwal S, Gurney AL. IL-17: prototype member of an emerging cytokine family. J Leukoc Biol 2002;71:1-8. [PubMed: 11781375]

14. Moseley TA, Haudenschild DR, Rose L, Reddi AH. Interleukin-17 family and IL-17 receptors. Cytokine Growth Factor Rev 2003;14:155-174. [PubMed: 12651226]

15. Kolls JK, Linden A. Interleukin-17 family members and inflammation. Immunity 2004;21:467-476. [PubMed: 15485625]

16. Schwandner R, Yamaguchi K, Cao Z. Requirement of tumor necrosis factor receptor-associated factor (TRAF)6 in interleukin 17 signal transduction. J Exp Med 2000;191:1233-1240. [PubMed: 10748240]

17. Ye $\mathrm{P}$, et al. Requirement of interleukin 17 receptor signaling for lung $\mathrm{CXC}$ chemokine and granulocyte colony-stimulating factor expression, neutrophil recruitment, and host defense. J Exp Med 2001;194:519-527. [PubMed: 11514607]

18. Nakae S, et al. Antigen-specific T cell sensitization is impaired in IL-17-deficient mice, causing suppression of allergic cellular and humoral responses. Immunity 2002;17:375-387. [PubMed: 12354389]

19. Nakae S, Nambu A, Sudo K, Iwakura Y. Suppression of immune iInduction of collagen-induced arthritis in IL-17-deficient mice. J Immunol 2003;171:6173-6177. [PubMed: 14634133]

20. Bush KA, Farmer KM, Walker JS, Kirkham BW. Reduction of joint inflammation and bone erosion in rat adjuvant arthritis by treatment with interleukin-17 receptor IgG1 Fc fusion protein. Arthritis Rheum 2002;46:802-805. [PubMed: 11920418]

21. Yao Z, et al. Human IL-17: a novel cytokine derived from T cells. J Immunol 1995;155:5483-5486. [PubMed: 7499828]

22. Aggarwal S, Ghilardi N, Xie MH, De Sauvage FJ, Gurney AL. Interleukin-23 promotes a distinct CD4 T cell activation state characterized by the production of interleukin-17. J Biol Chem 2003;278:1910-1914. [PubMed: 12417590]

23. Langrish CL, et al. IL-23 drives a pathogenic T cell population that induces autoimmune inflammation. J Exp Med 2005;201:233-240. [PubMed: 15657292]

24. Seder RA, Ahmed R. Similarities and differences in $\mathrm{CD} 4^{+}$and $\mathrm{CD} 8^{+}$effector and memory $\mathrm{T}$ cell generation. Nat Immunol 2003;4:835-842. [PubMed: 12942084]

25. Yang J, Murphy TL, Ouyang W, Murphy KM. Induction of interferon- $\gamma$ production in Th1 CD4 ${ }^{+} \mathrm{T}$ cells: evidence for two distinct pathways for promoter activation. Eur J Immunol 1999;29:548-555. [PubMed: 10064070]

26. Prasad DV, Richards S, Mai XM, Dong C. B7S1, a novel B7 family member that negatively regulates T cell activation. Immunity 2003;18:863-873. [PubMed: 12818166]

27. Ruddy MJ, et al. Functional cooperation between interleukin-17 and tumor necrosis factor- $\alpha$ is mediated by CCAAT/enhancer-binding protein family members. J Biol Chem 2004;279:2559-2567. [PubMed: 14600152]

28. Sun M, et al. Characterization of mouse and human B7-H3 genes. J Immunol 2002;168:6294-6297. [PubMed: 12055244] 
29. Ransohoff RM. The chemokine system in neuroinflammation: an update. J Infect Dis 2002;186:S152S156. [PubMed: 12424691]

30. Huang D, Wang J, Kivisakk P, Rollins BJ, Ransohoff RM. Absence of monocyte chemoattractant protein 1 in mice leads to decreased local macrophage recruitment and antigen-specific $\mathrm{T}$ helper cell type 1 Immune response in experimental auto-immune encephalomyelitis. J Exp Med 2001;193:713726. [PubMed: 11257138]

31. Vignola AM, et al. Sputum metalloproteinase-9/tissue inhibitor of metalloproteinase-1 ratio correlates with airflow obstruction in asthma and chronic bronchitis. Am J Respir Crit Care Med 1998;158:1945-1950. [PubMed: 9847290]

32. Beeh KM, Beier J, Kornmann O, Buhl R. Sputum matrix metalloproteinase-9, tissue inhibitor of metalloprotinease-1, and their molar ratio in patients with chronic obstructive pulmonary disease, idiopathic pulmonary fibrosis and healthy subjects. Respir Med 2003;97:634-639. [PubMed: 12814147]

33. Infante-Duarte C, Horton HF, Byrne MC, Kamradt T. Microbial lipopeptides induce the production of IL-17 in Th cells. J Immunol 2000;165:6107-6115. [PubMed: 11086043]

34. Linden A. Role of interleukin-17 and the neutrophil in asthma. Int Arch Allergy Immunol 2001;126:179-184. [PubMed: 11752873]

35. Stark MA, et al. Phagocytosis of apoptotic neutrophils regulates granulopoiesis via IL-23 and IL-17. Immunity 2005;22:285-294. [PubMed: 15780986]

36. Zhu Z, et al. Pulmonary expression of interleukin-13 causes inflammation, mucus hypersecretion, subepithelial fibrosis, physiologic abnormalities, and eotaxin production. J Clin Invest 1999;103:779-788. [PubMed: 10079098]

37. Ideker T, Thorsson V, Siegel AF, Hood LE. Testing for differentially-expressed genes by maximumlikelihood analysis of microarray data. J Comput Biol 2000;7:805-817. [PubMed: 11382363]

38. Dong C, et al. ICOS co-stimulatory receptor is essential for T-cell activation and function. Nature 2001;409:97-102. [PubMed: 11343121] 

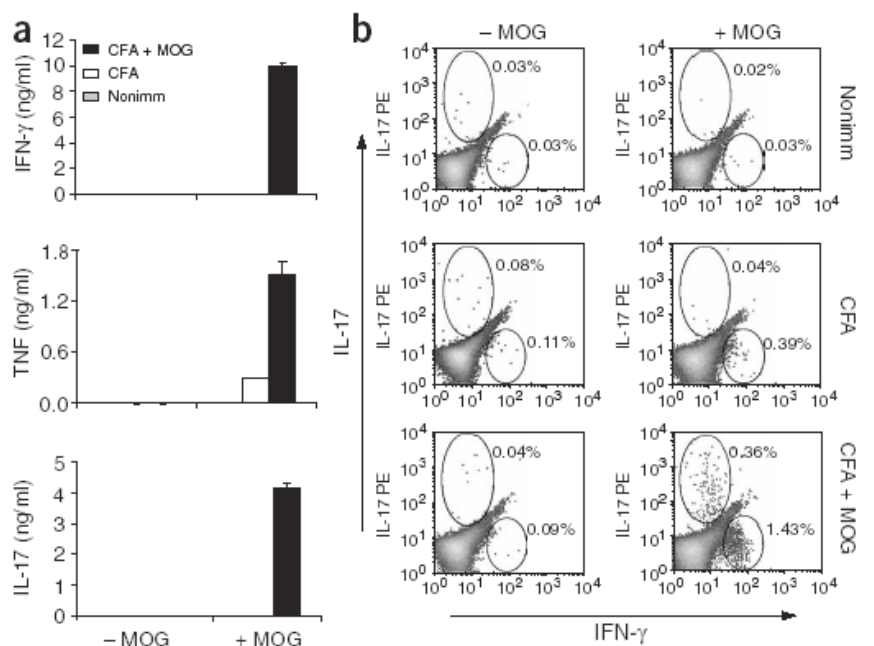

e
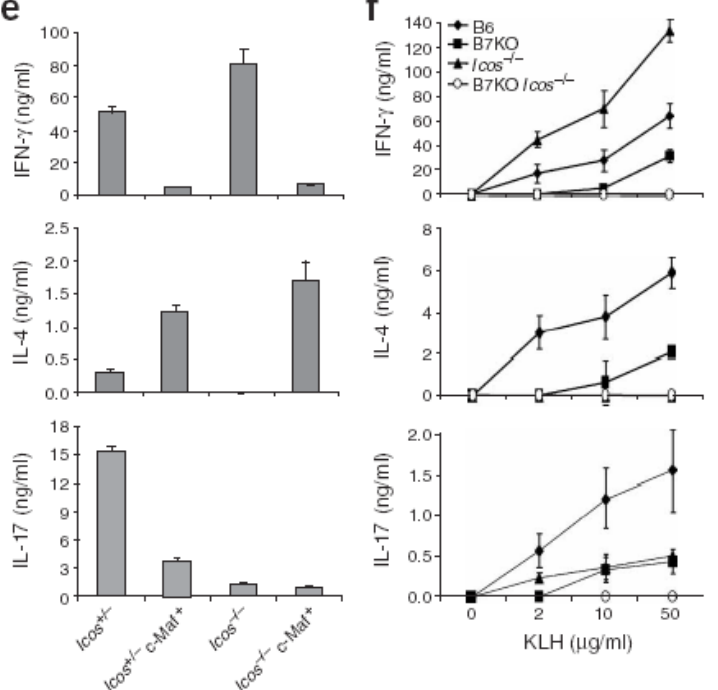

Figure 1.

The generation of IL-17-producing T cells requires CD28 and ICOS costimulation. (a,b) B6 mice were immunized with MOG(35-55) in CFA or CFA alone; $7 \mathrm{~d}$ later, lymph node and spleen cells from immunized mice (two mice in each group) were collected. (a) ELISA of cytokines in supernatants of lymph node and spleen cells from nonimmunized (Nonimm) and immunized mice stimulated in triplicate with MOG peptide for $72 \mathrm{~h}$ in vitro. (b) Intracellular staining for IL-17, IFN- $\gamma$ or TNF after MOG restimulation. Data are of gated $\mathrm{CD}^{+}$cells; numbers beside outlined areas indicate percent positive cells in that area. (c) Intracellular detection of IL-17 and IFN- $\gamma$ in conjunction with anti-CD4 or anti-CD8. B6 mice were immunized for $7 \mathrm{~d}$ with KLH in CFA and then spleen and lymph node cells were collected and restimulated with PMA and ionomycin. Numbers beside outlined areas indicate percent positive cells in that area. (d) ELISA of cytokine production by CD4 T cells isolated from Icossufficient $\left(\mathrm{ICOS}^{+/+}\right)$or Icos-deficient $\left(\operatorname{Icos}^{-1-}\right)$ OTII mice and activated for $4 \mathrm{~d}$ with splenic APCs from B6 mice (B7 WT) or mice doubly deficient in B7.1 and B7.2 (B7 KO) in the presence of OVA peptide; activated cells were then washed and restimulated for $24 \mathrm{~h}$ with antiCD3. (e) ELISA of cytokine production by naive T cells isolated from $I \cos ^{+/ 1}$ and $I \cos ^{-/-}$mice 
with or without the $M a f$ transgene and activated for $4 \mathrm{~d}$ with anti-CD3, APCs and IL-2. (f) ELISA of cytokine production by spleen cells isolated from B6, B7-deficient (B7 KO), $\mathrm{Icos}^{-1-}$ or B7-deficient $\mathrm{Icos}^{-1-}$ mice (three in each group, analyzed individually) immunized with KLH in CFA; spleen cells were restimulated ex vivo with various doses of KLH. Data are representative of at least two independent experiments with similar results. 
a

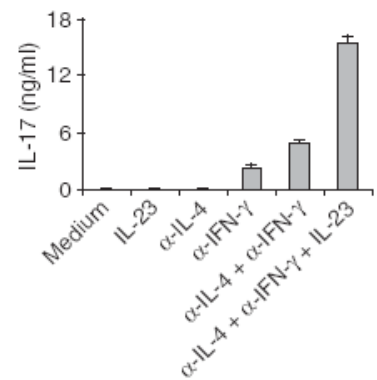

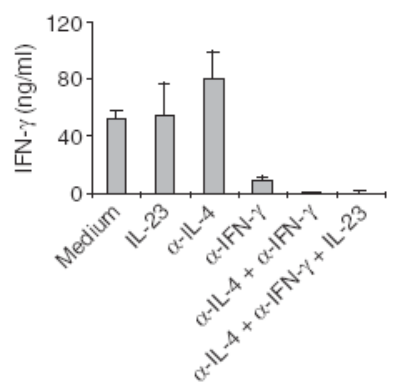
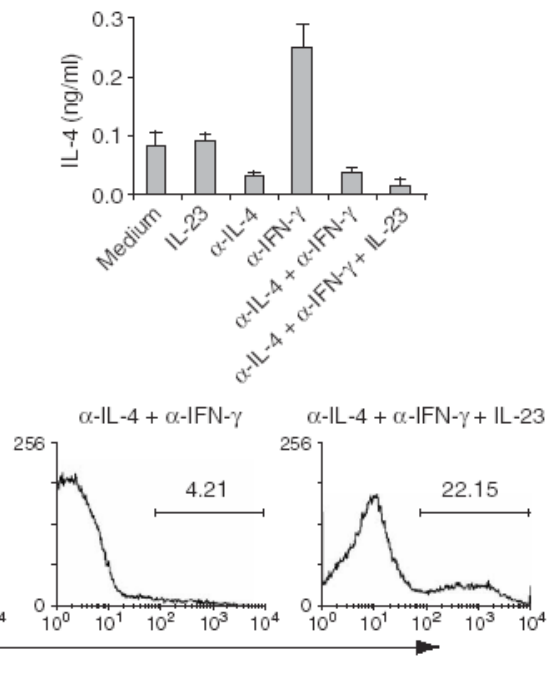

b
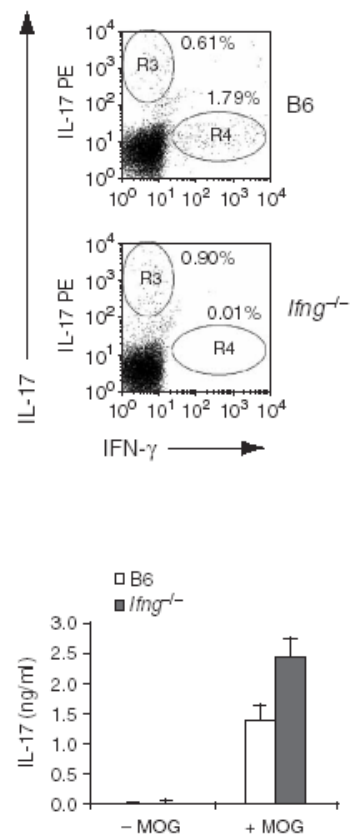

C
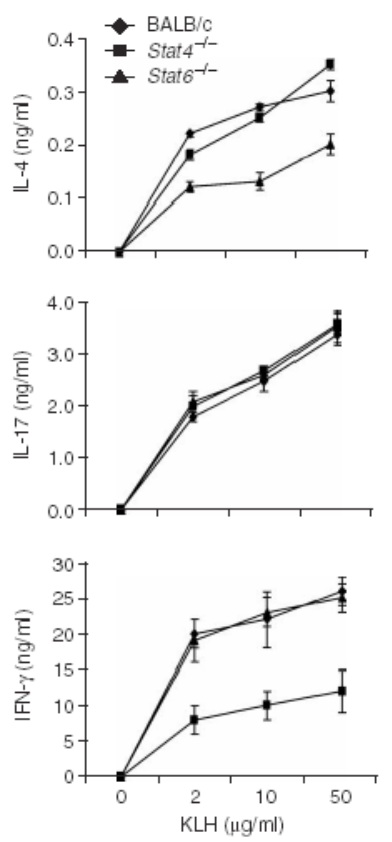

d
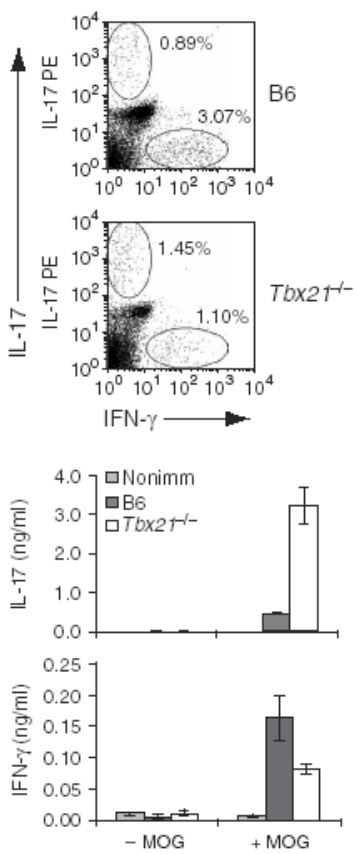

Figure 2.

Regulation of IL-17 expression by cytokines and transcriptional factors. (a) ELISA (top) and intracellular staining (bottom) to assess cytokine production by OTII cells. Naive T cells isolated from OTII mice were cultured for $5 \mathrm{~d}$ together with APCs from B6 mice along with $10 \mu \mathrm{g} / \mathrm{ml}$ of OVA peptide in presence or absence of anti-IL-4 ( $\alpha$-IL-4), anti-IFN- $\gamma(\alpha-I F N-\gamma)$ or IL-23. Cells were restimulated for $24 \mathrm{~h}$ with anti-CD3 for ELISA or for $5 \mathrm{~h}$ with PMA and ionomycin for intracellular staining. (b) Flow cytometry (dot plots) and ELISA (graph) of spleen and lymph node cells collected from MOG-immunized B6 and Ifng ${ }^{-1-}$ mice (two per group), analyzed with a $\mathrm{CD} 4^{+}$gate for expression IL-17 and IFN- $\gamma$ after MOG restimulation. (c) ELISA of cytokine expression by spleen and lymph node cells from BALB/c, STAT4deficient $\left(\right.$ Stat $\left.^{-/-}\right)$and STAT6-deficient $\left(\right.$Stat $\left.^{-/-}\right)$mice immunized with KLH in CFA, analyzed $7 \mathrm{~d}$ later after ex vivo restimulation of cells with KLH. (d) Intracellular staining (dot plots) or ELISA (graphs) of cytokine production by draining lymph node cells and splenocytes from T-bet-knockout mice $\left(\mathrm{Tb} \times 2 \mathrm{I}^{--}\right)$and B6 mice immunized with MOG in CFA at the tail 
base and analyzed 7 later. Numbers above bracketed lines (a) or beside oval areas (b,d) indicate percent of cells in that area. Data are representative of at least two independent experiments with similar results. 

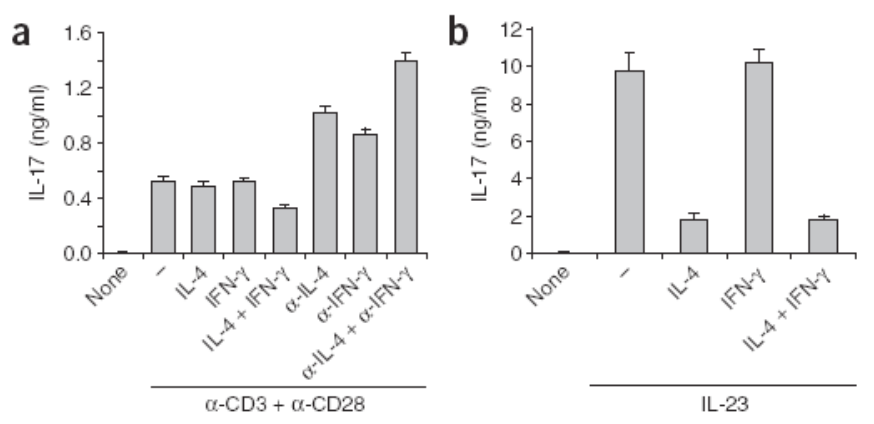

Figure 3.

Regulation of IL-17 production by effector and memory T cells. (a) ELISA of IL-17 production by enriched $\mathrm{CD}_{2} \mathrm{~L}^{-} \mathrm{CD}^{+}$cells treated for $36 \mathrm{~h}$ with various stimuli (horizontal axis) in the presence or absence of plate-bound anti-CD3 and anti-CD28. (b) ELISA of IL-17 production by sorted $\mathrm{CD} 62 \mathrm{~L}^{-} \mathrm{CD} 4^{+}$cells preactivated with plate-bound anti-CD3, washed and then treated for $24 \mathrm{~h}$ with various stimuli (horizontal axis) plus IL-23. None, absence of anti-CD3 plus antiCD28; -, without other stimuli. Data are representative of two experiments. 


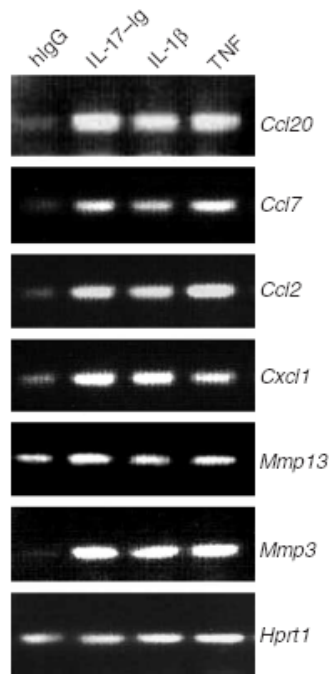

Figure 4.

IL-17 regulates genes encoding inflammatory molecules. RT-PCR of the expression of chemokines and matrix metalloproteinases (genes, right margin) in MEFs stimulated for $6 \mathrm{~h}$ with human IgG (hIgG), IL-17-Ig, IL-1 $\beta$ or TNF. 

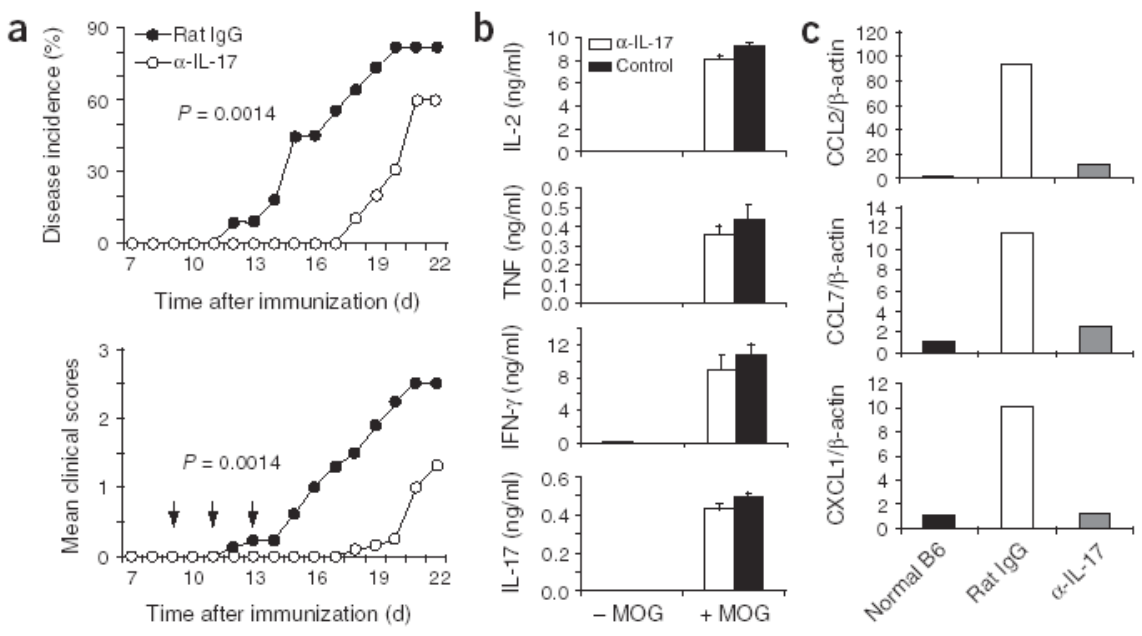

\section{Figure 5.}

IL-17 regulates chemokine expression in brain tissue during EAE. Anti-IL-17 or control rat $\operatorname{IgG}(100 \mu \mathrm{g} /$ mouse $)$ was administered intraperitoneally to mice with EAE on days 9,11 and 13 after the first MOG immunization. (a) EAE incidence is reduced by treatment with antiIL-17 ( $\alpha$-IL-17). Data are representative of two independent experiments; anti-IL-17, $n=10$ mice, and control, $n=11$ mice. Mean clinical scores of sick mice are for nine and six mice for the control and anti-IL-17 groups, respectively. (b) ELISA of proinflammatory cytokines in spleen and lymph node cells from control or anti-IL-17-treated mice (at least three in each group) restimulated for $72 \mathrm{~h}$ in triplicate in vitro with MOG and analyzed on day 18 after MOG immunization. Data combine more than three mice in each group. (c) Taqman PCR expression of chemokines CCL2, CCL7 and CXCL1 in brains from normal B6 mice and mice subjected to EAE and treated with rat IgG or anti-IL-17. Results are normalized to $\beta$-actin expression and were analyzed in triplicate. Expression in normal mice was considered to be 1 . 
a
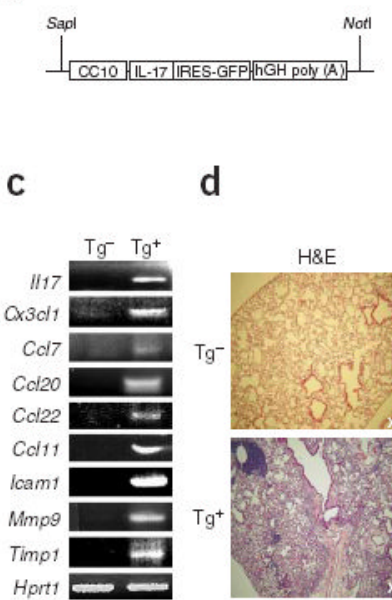

d

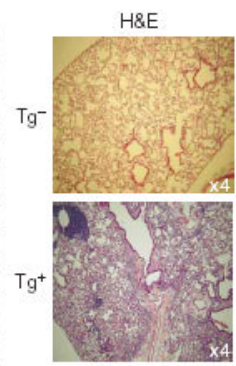

b

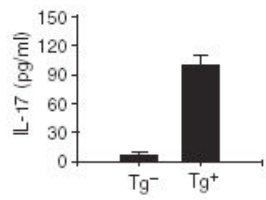

PAS

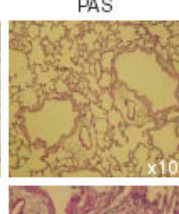
Trichrome

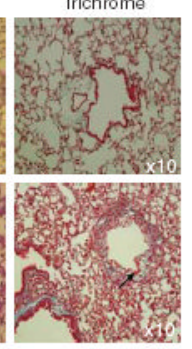

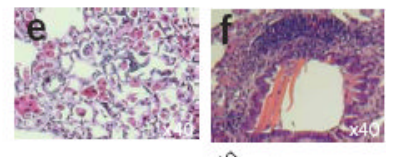

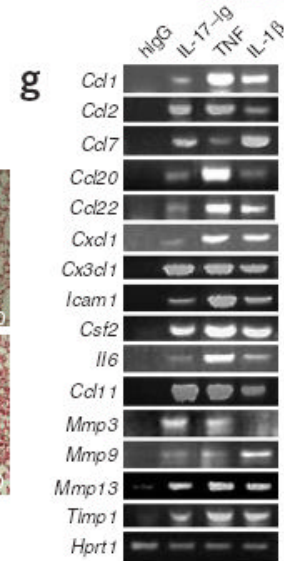

Figure 6.

Generation and analysis of Cc10-Ill7-transgenic mice. (a) CC10-IL-17 construct. hGH, human growth hormone. (b) ELISA of IL-17 in bronchoalveolar lavage fluid collected from transgene-positive mice $\left(\mathrm{Tg}^{+}\right)$and transgene-negative littermates $\left(\mathrm{Tg}^{-}\right)$. (c) RT-PCR of mRNA (genes, left margin) in lungs obtained from 5-month-old transgene-positive and transgenenegative mice. (d-f) Histological comparison of lung tissue. Lungs from 10-month-old transgene-positive and transgene-negative mice (d) or 10-month-old (e) or 5-month-old (f) transgene-positive mice are stained with hematoxylin and eosin $(\mathrm{H} \& \mathrm{E})$; with periodic acid Schiff (PAS) to compare mucus production in airway epithelium; and with Masson's trichrome staining to compare airway collagen deposition. Arrows, blue-staining collagen. (g) RT-PCR of expression of genes (left margin) in MLE12 cells treated for $6 \mathrm{~h}$ with various stimuli (above lanes). Csf 2 encodes granulocyte colony-stimulating factor. 


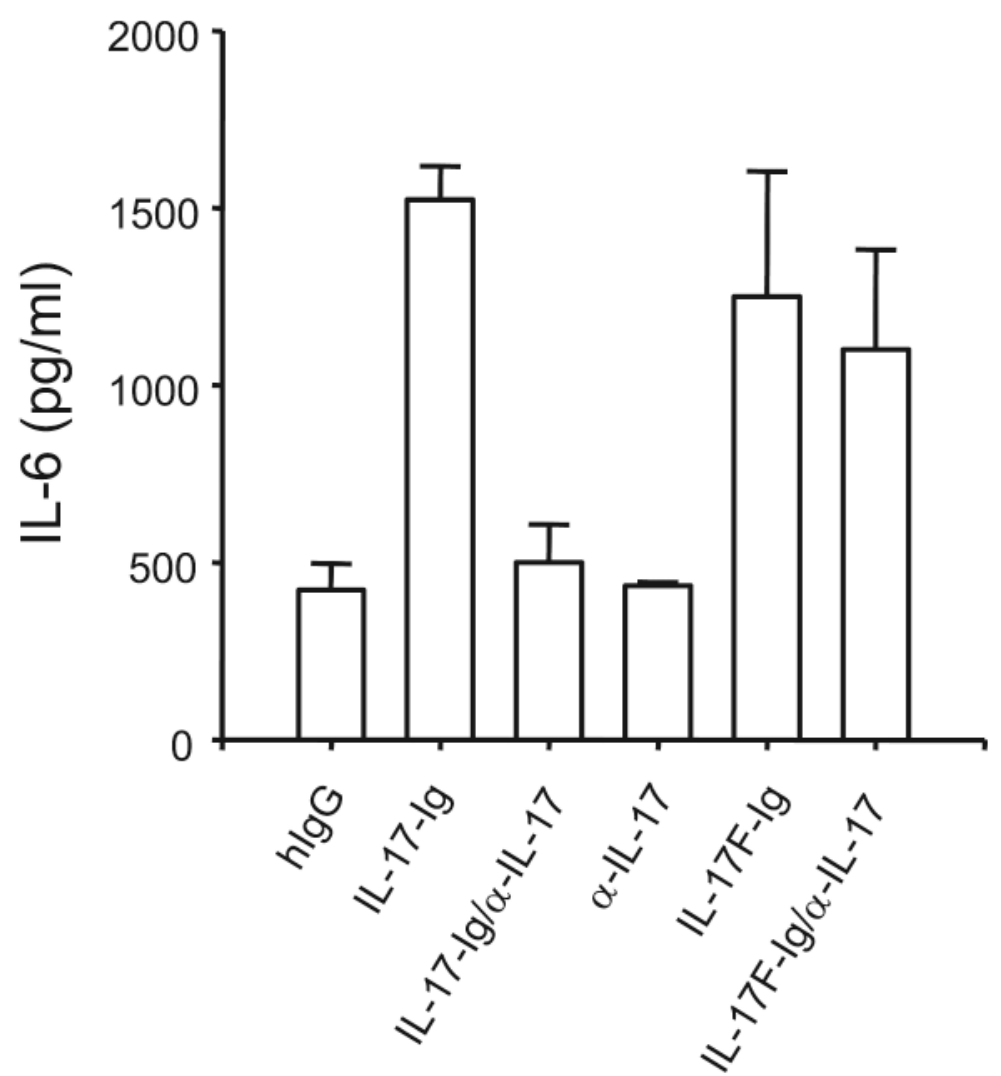

Supplementary Figure 1. Anti-IL-17 antibody specifically blocks IL-17 biological activity MEF were treated with $500 \mathrm{ng} / \mathrm{ml}$ IL-17-Ig, IL-17F-Ig or human IgG in the presence of a rat Ig control or anti-IL-17 for 24 hrs. IL-6 production was measured by ELISA. 
a
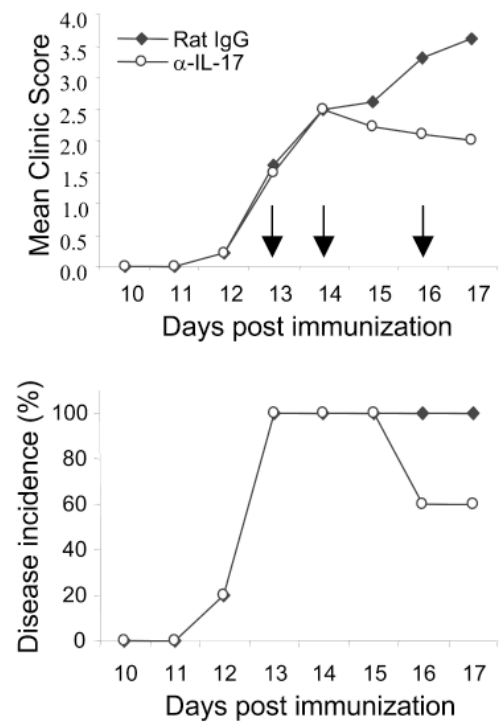

b

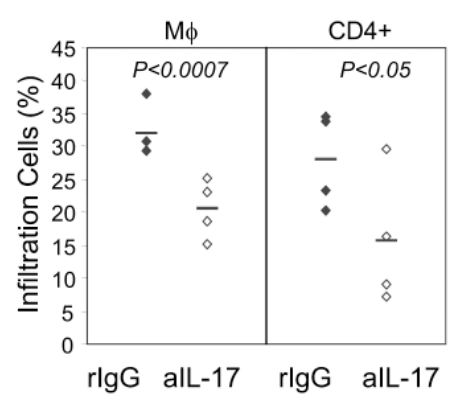

c
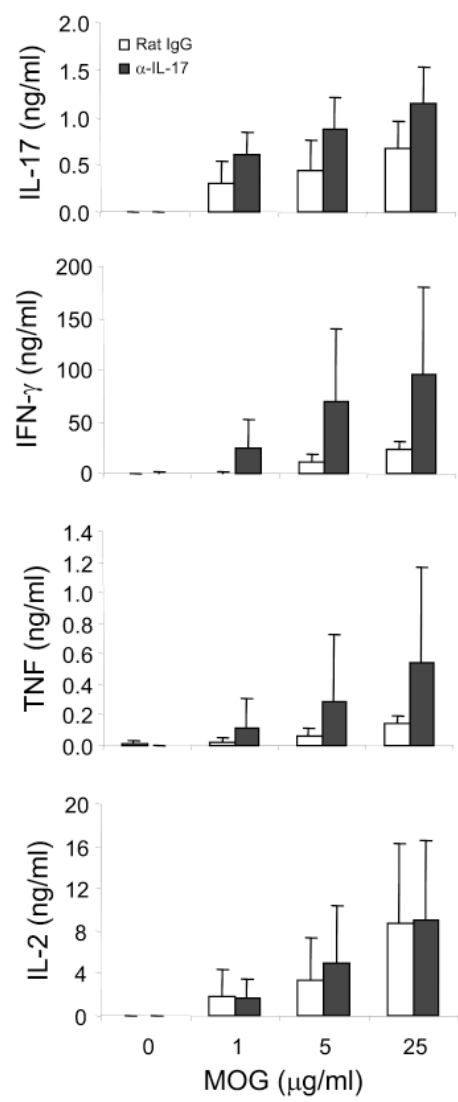

d

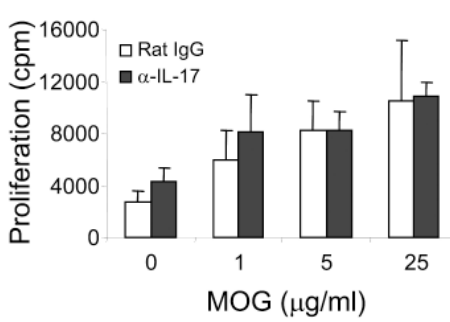

Supplementary Figure 2. Blockage of IL-17 after disease onset reduces inflammation during EAE (a) Anti-IL-17 treatment attenuates EAE incidence and severity. C57BL/6 mice were immunized with MOG/CFA and administered with pertussis toxin (see "Experimental Procedures"). Three doses of anti-IL-17 or rat IgG was administered after the disease onset (clinic score $>1$ ) on day 13, 14 and 16 post first immunization shown as arrows ( $\mathrm{n}=5$ in each group). (b) Less infiltration of CD4 T cells and macrophages were observed in anti-IL17 treatment group than rat IgG group. On day 17, mononuclear cells isolated from brains and spinal cords were analyzed for surface markers CD11b and CD4. Student $t$-test is shown as $P$ values. (c) Splenocytes were ex vivo restimulated with MOG for 48 hours and cytokines expression were measured by ELISA. (d) Splenocyte proliferation in anti-IL-17 treatment group was similar with control group. 


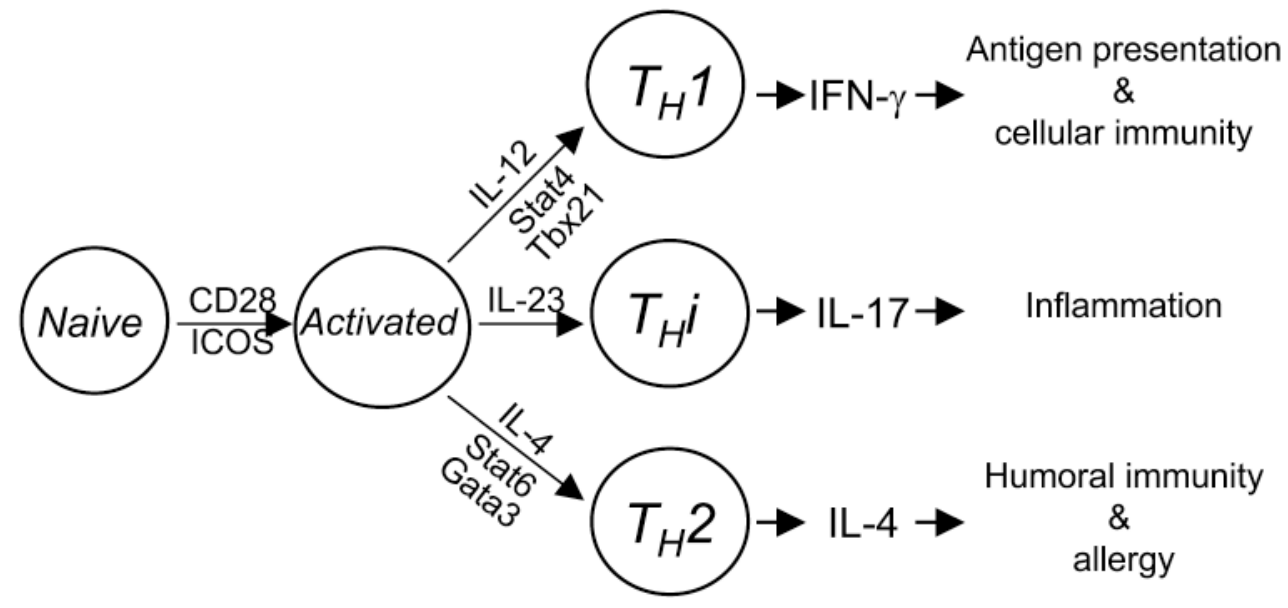

Supplementary Figure 3. Summary of $\mathbf{T}_{H}$ differentiation $\mathrm{T}_{\mathrm{H}} \mathrm{i}$ is a novel arm of $\mathrm{T}_{\mathrm{H}}$ cells. Cytokine and transcription factor for $\mathrm{T}_{\mathrm{H}}$ progenitor to differentiate into $T_{H} i$ cells are distinct from those required by conventional $T_{H} 1$ and $T_{H} 2$. 
Table 1

Upregulation of genes in MEFs after treatment with IL-17-Ig

\begin{tabular}{llr}
\hline Accession code $^{\boldsymbol{a}}$ & Gene symbol $^{\boldsymbol{b}}$ & 'Fold increase $^{\boldsymbol{c}}$ \\
\hline NM_011333 & Ccl2 (small inducible cytokine A2) & 3.22 \\
NM_013654 & Ccl7 (small inducible cytokine A7) & 2.40 \\
NM_016960 & Ccl20 (small inducible cytokine subfamily A20) & 2.32 \\
NM_009142 & Cx3cll (small inducible cytokine subfamily D1) & 1.76 \\
NM_008176 & Cxcll (Gro1 oncogene) & 3.85 \\
NM_008607 & Mmp13 (matrix metalloproteinase 13) & 2.87 \\
NM_010809 & Mmp3 (matrix metalloproteinase 3) & 2.89 \\
\hline
\end{tabular}

${ }^{a}$ GenBank accession numbers.

${ }^{b}$ In parentheses, molecule encoded by gene.

${ }^{c}$ Data represent the increase in gene expression. 